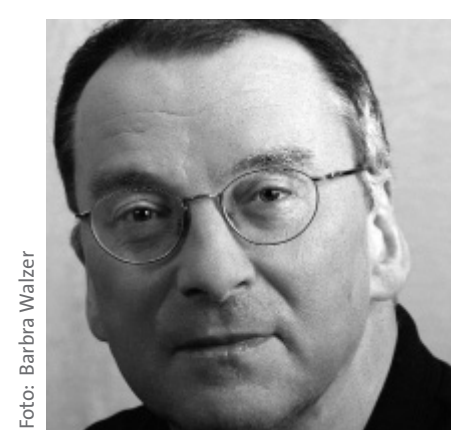

\title{
Attraktives Konzept
}

Das Zitat des französischen Dichters des »Kleinen Prinzen «, Antoine de SaintExupéry, mag abgegriffen sein; richtig ist es nach wie vor: » Wenn du ein Schiff bauen willst, dann trommle nicht Männer zusammen, um Holz zu beschaffen, Aufgaben zu vergeben und die Arbeit einzuteilen, sondern lehre sie die Sehnsucht nach dem weiten, endlosen Meer. « Wenn Führungskräfte scheitern, scheitern sie selten an Strukturen, Gesetzen oder Finanzen, sondern an Menschen: an gekränkten Aufsichtsräten, an sich benachteiligt fühlenden Mitarbeiterinnen und Mitarbeitern, an vernachlässigten Kunden und Kooperationspartnern. Das ist in der Sozialwirtschaft nicht anders. Deshalb ist die Feststellung vom Personal als wichtigstem Gut eines Unternehmens über Sonntagsreden hinaus von zutreffender Bedeutung. Die sich abzeichnende und in einigen Branchen und Regionen bereits spürbare Personalnot verlangt deshalb ein grundsätzliches Umdenken im Management. Sascha Weber zeigt in seinem Beitrag in diesem Heft, was Steuerungskonzepte zur Bewältigung des Fachkräftemangels in sozialen Organisationen beitragen können. Dazu gehört die Auflösung traditioneller Hierarchien, in denen einer Arbeitsstelle bestimmte Aufgaben - und damit Zeitbudgets sowie eine Gesamtvergütung - fest zugeordnet sind. Stattdessen schlägt er eine Aufgabenorganisation vor, in der die einzelnen Aufgaben disponibel sind. Jeder Aufgabe ist eine Zugangsvoraussetzung und ein Zeitraum (»Verfalldatum «) sowie ein Zeit- und Vergütungsbudget (gedacht als Zuschlag auf eine Grundvergütung) zugeordnet. Dieses Konzept hilft dem Management und es ist attraktiv für Menschen, die sich überlegen, wo sie ihr Arbeitsleben verbringen wollen.

Gerhard Pfannendörfer, Chefredaktion

E-Mail pfannendoerfer@googlemail.com Internet http://www.sozialwirtschaft.nomos.de 